\title{
EFEITOS DA ADUBAĈ̃O ORGÂNICA E DA ÉPOCA DE COLHEITA NA QUALIDADE DA MATÉRIA-PRIMA E NOS RENDIMENTOS AGRÍCOLA E DE AÇÚCAR MASCAVO ARTESANAL DE DUAS CULTIVARES DE CANA-DE-AÇÚCAR (CANA-PLANTA)
}

\author{
Effects of organic fertiliser and harvest date on quality and agricultural yield and \\ of raw-sugar of two sugarcane cultivar (plant cane)
}

\author{
Ivan Antônio dos Anjos ${ }^{1}$, Luiz Antônio de Bastos Andrade², Julio César Garcia ${ }^{1}$, \\ Paulo Alexandre Monteiro de Figueiredo ${ }^{3}$, Gabriel José de Carvalho²
}

\begin{abstract}
RESUMO
Conduziu-se este trabalho com o objetivo de estudar os efeitos de três sistemas de adubação (30 t. ha-1 de esterco de curral, 3,5 t.ha ${ }^{-1}$ de esterco de galinha e adubação química - $120 \mathrm{~kg}^{-h a^{-1}}$ de $\mathrm{P}_{2} \mathrm{O}_{5}$ e de $\mathrm{K}_{2} \mathrm{O}$ no plantio $+60 \mathrm{~kg} \cdot \mathrm{ha}^{-1}$ de N em cobertura) e três épocas de colheita da cana (julho, agosto e setembro de 2003), na qualidade da matéria-prima e nos rendimentos de colmos e de açúcar mascavo de duas cultivares de cana-de-açúcar (SP79-1011 e RB72454). O experimento foi instalado em área do Alambique JM, Perdões, MG. O delineamento experimental foi o de blocos casualizados, em esquema fatorial $(2 \times 3 \times 3)$, com três repetições. Não houve efeito dos fertilizantes nos rendimentos de colmos e de açúcar mascavo das cultivares estudadas. Verificou-se efeito de épocas de colheita no rendimento de colmos, com destaque para os meses de agosto e setembro. No entanto, para rendimento de açúcar mascavo nenhuma diferença foi observada. Assim, nas condições deste trabalho, é viável a substituição da adubação química pela orgânica (esterco de curral ou de galinha), sem perdas na qualidade da matéria-prima e nos rendimentos de colmos e de açúcar mascavo artesanal, sendo que os meses de agosto e setembro foram os que proporcionaram matéria-prima de melhor qualidade e maiores rendimentos de colmos.
\end{abstract}

Termos para indexação: Cana-de-açúcar, adubação orgânica, açúcar artesanal.

\begin{abstract}
The objective of this work was to study the effects of three fertilizers process (30 t. ha ${ }^{-1}$ of corral manure, 3,5 t.ha ${ }^{-1}$ of chicken manure and chemical fertilizer $-120 \mathrm{~kg}$.ha- 1 of $\mathrm{P}_{2} \mathrm{O}_{5}$ and of $\mathrm{K}_{2} \mathrm{O}$ at planting time $+60 \mathrm{~kg} \cdot \mathrm{ha}^{-1}$ of $\mathrm{N}$ in covering) and three harvest dates (July, August and September of 2003), in the agricultural yield and of raw-sugar of two sugarcane cultivars (SP79-1011 and RB72454). The experiment was carried out in Alambique JM farm in Perdões, MG, Brazil. The experimental design was a factorial $2 \times 3 \times 3$, in randomized blocks, with three replications. No effects of the fertilizers studied in the agricultural yield and of raw-sugar of the cultivars were verified. There was effect of harvest dates in the yield of stems of the cultivars, with prominence for the month of August and September. However, the yield of raw-sugar was not affected. Thus, in the conditions applied to this work, the small producers can choose for one of the studied ways of organic fertilizer, since they did not differentiated from the chemical fertilizer, and the months of August and September were that which provided larger stems yield, and sugarcane quality.
\end{abstract}

Index terms: Sugarcane, organic fertilizer, raw-sugar.

(Recebido para publicação em 20 de setembro de 2005 e aprovado em 18 de julho de 2006)

\section{INTRODUÇÃO}

Hoje, a maior parte das unidades produtoras de açúcar e de álcool ainda utiliza a adubação mineral, como fonte de nutrientes, na cultura canavieira. Porém, já é notória a preocupação em se obter um novo produto, de maior valor agregado, por algumas unidades que utilizam o sistema de adubação orgânica ou quase totalmente orgânica.

Matsuoka et al. (2002) afirmam que a produção de cana orgânica é viável, pois conseguem-se produtividades agrícolas similares às obtidas com adubação mineral.
O açúcar produzido organicamente, seja do tipo cristalizado obtido em usinas, seja do tipo mascavo oriundo de empresas de médio porte ou de pequenas empresas familiares, tem tido uma grande aceitação (DELGADO \& DELGADO, 1999).

A região Sul de Minas Gerais caracteriza-se por pequenas propriedades que têm na produção de cachaça, rapadura, açúcar mascavo e melado uma atividade complementar à da produção de leite, predominante na região, mas faltam informações técnicas a respeito.

Dentre os adubos orgânicos disponíveis na região e que podem ser usados na cultura canavieira, barateando

\footnotetext{
${ }^{1}$ Pesquisadores da APTA/IAC-SP - Cetro Avançado de Pesquisa Tecnológica do Agronegócio de Cana - Anel Viário Contorno Sul, km 321 - Cx. P. 206 14.001-970 - Ribeirão Preto, SP.

2Professores do Departamento de Agricultura/DAG da Universidade Federal de Lavras/UFLA - Cx. P. 3037 - $37200-000$ - Lavras, MG - laba@ufla.br ${ }^{3}$ Professor da Universidade Estadual Paulista/UNESP - Campus de Dracena - Rua Bahia, 332 - Dracena, SP.
} 
os custos de produção, destacam-se o esterco de curral e o de galinha, aplicados principalmente no sulco de plantio. Andrade (1998) afirma que o uso de estercos poderá até mesmo substituir a adubação química de plantio.

O momento adequado para se efetuar a colheita da cana é de suma importância, pois espera-se que o potencial produtivo seja melhor explorado, porém, com o cultivo orgânico da cultura pouco se sabe quanto aos efeitos dos adubos orgânicos no comportamento das cultivares no decorrer do período de colheita.

Assim, visou-se com este trabalho, estudar a produtividade agrícola, a qualidade da matéria-prima e o rendimento do açúcar mascavo artesanal de duas cultivares de cana-de-açúcar, cultivadas em sistemas de adubação mineral ou orgânica e colhidas em três épocas.

\section{MATERIAL E MÉTODOS}

$\mathrm{O}$ experimento foi instalado no mês de março de 2002, em área do Alambique João Mendes - "JM", município de Perdões, Minas Gerais, em um Latossolo Vermelho-Amarelo distrófico, textura média, cultivado até então com pastagem de capim-braquiária (Brachiaria decumbens Stapf).

O delineamento experimental foi o de blocos casualizados, em esquema fatorial $2 \times 3 \times 3$, com três repetições. O primeiro fator foi constituído por duas cultivares de cana-de-açúcar de ciclo de maturação média - SP79-1011 ou de maturação média/tardia - RB72454 as quais estão entre aquelas atualmente recomendadas no Sul de Minas Gerais para produção de açúcar e de álcool.

O segundo fator foi constituído por três formas de adubação (esterco de curral - 30 t.ha $^{-1}$, esterco de galinha $-3,5$ t.ha- ${ }^{-1}$ e adubo mineral $-120 \mathrm{~kg} \cdot \mathrm{ha}^{-1}$ de $\mathrm{P}_{2} \mathrm{O}_{5}$ e 120 $\mathrm{kg} \cdot \mathrm{ha}^{-1}$ de $\mathrm{K}_{2} \mathrm{O}$ no plantio e $60 \mathrm{~kg} \cdot \mathrm{ha}^{-1}$ de $\mathrm{N}$ em cobertura) e o terceiro fator foi constituído por três épocas de colheita ( meados de julho, agosto e setembro de 2003).

A parcela foi constituída por seis linhas de plantio, espaçadas de 1,40 m entre si, com comprimento de 8,0 m, com área total de $67,20 \mathrm{~m}^{2}$. A colheita foi realizada de forma manual sem queima prévia. No momento das respectivas épocas de colheita, doze colmos seguidos na linha foram colhidos em cada parcela, sendo os mesmos enfeixados e enviados para o laboratório da Destilaria Alvorada do Bebedouro, Guaranésia-MG, para análises químico-tecnológicas (brix e pol (\%) cana).

A produtividade de colmo, foi determinada segundo metodologia preconizada por Mariotti \& Lascano (1969), citados por Arizono et al. (1998).
Em seguida, realizou-se a moagem da cana-deaçúcar para obtenção do caldo para processamento do açúcar. Após a moagem da cana o caldo foi purificado, sendo em seguida conduzido para tachos em cobre, para o cozimento, o qual foi processado em sistema de fogo direto. Para detectar o final do processo de cozimento, empregou-se o método da "prova da bala". Posteriormente o xarope foi transferido para um cocho de madeira para bateção e resfriamento, reduzindo-o assim a uma massa solta de açúcar. Em seguida os grânulos foram peneirados, secos e acondicionados em sacos etiquetados e identificados, os quais foram pesados para determinação dos rendimentos de açúcar mascavo, fazendo-se posteriormente a transformação para t.ha- ${ }^{-1}$.

\section{RESULTADOS E DISCUSSÃO}

\section{Teores de brix e pol (\%) cana}

As análises estatísticas para brix e pol $(\%)$ cana mostraram efeitos significativos para a interação cultivares $\mathrm{x}$ adubação $\mathrm{x}$ épocas de colheita; os valores médios obtidos para brix e pol (\%) cana de duas cultivares de cana-deaçúcar em função de diferentes sistemas de adubação e em diferentes épocas de colheita são apresentados na Tabela 1.

Verifica-se que para as duas cultivares, (SP79-1011 e RB72454) nas três épocas, (julho, agosto, setembro) os valores obtidos para brix e pol (\%) cana foram estatisticamente iguais quando se compara a aplicação do esterco de curral com a adubação química, mostrando que a dose de esterco de curral utilizada não afetou a maturação da cana-de-açúcar. O mesmo aconteceu comparando-se o uso de esterco de galinha, e o de adubo mineral para as duas cultivares, nas duas primeiras épocas de corte (julho e agosto).

Na tabela 2, são apresentadas as médias dos valores de brix e pol (\%) cana das duas cultivares de canade-açúcar nos três sistemas de adubação, em cada uma das épocas de colheita.

De maneira geral, verifica-se pela Tabela 2 , que as médias obtidas para brix e pol $(\%)$ cana na $2^{\text {a época }}$

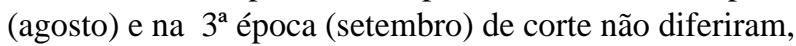
mas foram superiores àquelas obtidas na $1^{\mathrm{a}}$ época (julho); o que era esperado, por se tratar de cultivares de maturação média (SP79-1011) ou média/tardia (RB72454), que normalmente atingem maiores valores nos meses de agosto e setembro. 
TABELA 1 - Valores médios obtidos para brix e pol (\%) cana de duas cultivares de cana-de-açúcar, em diferentes sistemas de adubação e em diferentes épocas de colheita. UFLA, Lavras-MG, 2005.

\begin{tabular}{llcccc}
\hline & & \multicolumn{3}{c}{ Brix (\%) cana } & \multicolumn{2}{c}{ Pol (\%) cana } \\
\hline \multirow{4}{*}{ Época 1 } & & SP79-1011 & RB 72454 & SP79-1011 & RB72454 \\
& Esterco de Curral & 17,04 a A & 17,23 ab A & 16,17 a A & 16,01 a A \\
& Esterco de Galinha & 17,45 a A & 17,37 a A & 16,38 a A & 15,94 a A \\
& Adubo Mineral & 17,48 a A & $16,70 \mathrm{~b} \mathrm{~B}$ & 16,44 a A & 15,83 a B \\
\hline \multirow{2}{*}{ Época 2 } & Esterco de Curral & 18,74 a A & 18,59 a A & 17,30 a A & 16,91 a A \\
& Esterco de Galinha & 18,83 a A & 18,84 a A & 17,43 a A & 17,42 a A \\
& Adubo Mineral & 18,38 a B & 18,90 a A & 17,00 a A & 17,28 a A \\
\hline \multirow{2}{*}{ Época 3 } & Esterco de Curral & 19,06 a A & 18,49 b B & 18,18 a A & $17,19 \mathrm{~b} \mathrm{~B}$ \\
& Esterco de Galinha & 18,45 b B & 19,21 a A & 16,82 b B & 18,06 a A \\
& Adubo Mineral & 18,68 ab A & 18,36 b A & 17,84 a A & 16,95 b B \\
\hline
\end{tabular}

Médias seguidas de mesma letra minúscula na coluna e maiúscula na linha não diferem entre si pelos testes de Tukey e de $\mathrm{F}$ respectivamente ao nível de $5 \%$ de significância.

TABELA 2 - Médias obtidas para brix e pol (\%) cana de duas cultivares de cana-de-açúcar, cultivadas em três sistemas de adubação, em cada uma das épocas de colheita. UFLA, Lavras-MG,2005.

\begin{tabular}{lcc}
\hline Época (mês) & Brix (\%) cana & Pol (\%) cana \\
\hline 1 (julho) & $17,21 \mathrm{~b}$ & $16,13 \mathrm{~b}$ \\
2 (agosto) & $18,71 \mathrm{a}$ & $17,22 \mathrm{a}$ \\
3 (setembro) & $18,71 \mathrm{a}$ & $17,50 \mathrm{a}$ \\
\hline
\end{tabular}

Médias seguidas de mesma letra minúscula na coluna não diferem entre si ao nível de $5 \%$ de probabilidade pelo teste Tukey.

\section{Rendimento de colmos e açúcar mascavo artesanal}

As análises estatísticas para rendimento de colmos mostraram efeitos significativos apenas para épocas de colheita; já para rendimento de açúcar mascavo nenhum dos fatores estudados e suas interações mostraram significância. Os valores médios obtidos para rendimento de colmos e de açúcar mascavo (t.ha- ${ }^{1}$ ) são apresentados na Tabela 3 .

As médias dos rendimentos de colmos (t.ha $\left.{ }^{-1}\right)$, das duas cultivares, nos três sistemas de adubação, em cada uma das épocas de colheita - julho, agosto e setembro, estão apresentadoa na Tabela 4. Nota-se que na colheita realizada em agosto, $2^{\mathrm{a}}$ época, as cultivares obtiveram, em média, maior rendimento, alcançando 83,46 t.ha ${ }^{-1}$, contra

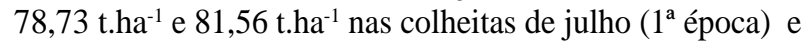
setembro ( $3^{a}$ época), respectivamente, não havendo, entretanto, diferenças significativas entre as $2^{\mathrm{a}}$ e $3^{\mathrm{a}}$ épocas. Anjos (2001) encontrou resultados semelhantes, na mesma região, para produção de aguardente artesanal.
Um fato importante é que, como os melhores resultados ocorreram na segunda e terceira épocas, meses de agosto e setembro, pode-se inferir que possivelmente não haverá grandes problemas para as brotações das socas subseqüentes, uma vez que Chavanne et al. (1994), citados por Raizer et al. (1999), mencionaram que estes são períodos favoráveis para a colheita da cana-planta, sem comprometimento na produtividade das soqueiras subseqüentes, já que estão próximos da época das chuvas.

De acordo com os resultados do presente trabalho, verifica-se que é viável a substituição da adubação química pela orgânica, sem que haja perda na qualidade e produtividade da matéria-prima e no rendimento de açúcar mascavo. Entretanto, torna-se necessário a continuidade do trabalho envolvendo a cana-soca e a realização de novos estudos de cultivares, adubação orgânica e épocas de colheita e suas interações. 
TABELA 3 - Valores médios obtidos para rendimentos de colmos ( $\mathrm{t}$. ha $\left.\mathrm{h}^{-1}\right)$ e de açúcar mascavo $\left(\mathrm{t}\right.$-ha $\left.{ }^{-1}\right)$ - de duas cultivares de cana-de-açúcar, cultivadas com esterco de curral, esterco de galinha ou adubação mineral, em diferentes épocas de colheita. UFLA, Lavras-MG, 2005.

\begin{tabular}{|c|c|c|c|c|c|}
\hline & & \multicolumn{2}{|c|}{ Rendimento de colmos (t.ha $\left.{ }^{-1}\right)$} & \multicolumn{2}{|c|}{ Rendimento de açúcar mascavo (t.ha $\left.{ }^{-1}\right)$} \\
\hline & & SP79-1011 & RB 72454 & SP79-1011 & RB 72454 \\
\hline \multirow{3}{*}{ Época 1} & Esterco de curral & 71,02 & 74,75 & 7,47 & 8,70 \\
\hline & Esterco de Galinha & 78,08 & 88,25 & 8,62 & 8,80 \\
\hline & Adubo Mineral & 80,24 & 80,02 & 7,53 & 8,93 \\
\hline \multirow{3}{*}{ Época 2} & Esterco de curral & 77,86 & 75,99 & 9,03 & 10,91 \\
\hline & Esterco de Galinha & 94,08 & 83,87 & 9,75 & 10,19 \\
\hline & Adubo Mineral & 80,17 & 88,77 & 9,03 & 11,96 \\
\hline \multirow{3}{*}{ Época 3} & Esterco de curral & 71,31 & 74,25 & 8,99 & 9,48 \\
\hline & Esterco de Galinha & 81,74 & 91,94 & 8,75 & 11,09 \\
\hline & Adubo Mineral & 76,77 & 93,37 & 9,05 & 6,61 \\
\hline
\end{tabular}

TABELA 4 - Médias obtidas para rendimento de colmos (t.ha-1) de duas cultivares de cana-de-açúcar cultivadas em três sistemas de adubação, em cada uma das épocas de colheita. UFLA, Lavras-MG, 2005.

\begin{tabular}{lc}
\hline Épocas & ${\left.\text { Rendimento de Colmos (t.ha }{ }^{-\mathbf{1}}\right)}^{-1}$ \\
\hline 1 (julho) & $78,73 \mathrm{~b}$ \\
2 (agosto) & $83,46 \mathrm{a}$ \\
3 (setembro) & $81,56 \mathrm{ab}$ \\
\hline
\end{tabular}

Médias seguidas de mesma letra minúscula , não diferem entre si ao nível de 5\% de probabilidade pelo teste de Tukey.

\section{CONCLUSÕES}

Nas condições do presente trabalho pode-se concluir que:

É viável a substituição da adubação química pela orgânica (esterco de curral ou de galinha) sem perdas na qualidade da matéria-prima e nos rendimentos de colmos e de açúcar mascavo artesanal, sendo que os meses de agosto e setembro foram os que proporcionaram matéria-prima de melhor qualidade e maiores rendimentos de colmos.

\section{AGRADECIMENTOS}

Agradecemos à Fundação de Amparo à Pesquisa de Minas Gerais - FAPEMIG pela concessão da Bolsa de recém-doutorado; ao Alambique João Mendes, Perdões - MG, na pessoa do Sr. João Batista Mendes e à Destilaria Alvorada do Bebedouro, Guaranésia - MG, pela realização das análises tecnológicas da cana-deaçúcar.

\section{REFERÊNCIAS BIBLIOGRÁFICAS}

ANDRADE, L. A. B. Cultura da cana-de-açúcar. In: Produção artesanal de aguardente. Lavras: UFLA/FAEPE, 1998. p. 1-30.

ANJOS, I. A. Produtividade agrícola, rendimento e qualidade da aguardente artesanal de diferentes variedades de cana-de-açúcar. 2001. 102 p. Tese (Doutorado) Universidade Federal de Lavras, Lavras, 2001.

ARIZONO, H.; MATSUOKA, S.; GHELLER, Y.; HOFFMANN, H. P.; BASSICHELLO, A. I.; MENESEZ, L. L. Alternativas para avaliação de produção de cana-deaçúcar. STAB, Açúcar, Álcool e Subprodutos, Piracicaba, v. 16 , n. 5 , p. 20, maio/jun. 1998.

DELGADO, A. A.; DELGADO, A. P. Produção do açúcar mascavo, rapadura e melaço. Piracicaba: Ed. Alves, 1999. $154 \mathrm{p}$. 
MATSUOKA, S.; MARGARIDO, L. A. C.; LAVORENTI, N. A.; ELIAS JÚNIOR, R.; PINELL, D. M. Comportamento de variedades de cana-de-açúcar em um sistema orgânico de produção. In: CONGRESSO NACIONAL DA STAB, 8., 2002, Recife. Anais... Recife: [s.n.], 2002. p. 301-308.
RAIZER, A. J.; SORDI, R. A.; BRAGA JÚNIOR, R. L. Avaliação de ensaios de competição de variedades colhidas em diferentes épocas de corte durante a safra. In: CONGRESSO NACIONAL DA STAB, 7., 1999, Paraná. Anais... Paraná: [s.n.], 1999. p. 40-43. 